$12-29-2017$

\title{
School-based oral health promotion and intervention in AMIGA (Alfonso, Mendez, Indang, General Emilio Aguinaldo, Amadeo) Cavite
}

Arlene Cecilia Alfaro

University of the Philippines Manila, aaalfaro@up.edu.ph

Follow this and additional works at: https://scholarhub.ui.ac.id/ajce

Part of the Social and Behavioral Sciences Commons

\section{Recommended Citation}

Alfaro, Arlene Cecilia (2017). School-based oral health promotion and intervention in AMIGA (Alfonso, Mendez, Indang, General Emilio Aguinaldo, Amadeo) Cavite. ASEAN Journal of Community Engagement, 1(2).

Available at: https://doi.org/10.7454/ajce.v1i2.72

Creative Commons License

(c) (i) ()

This work is licensed under a Creative Commons Attribution-Share Alike 4.0 License.

This Research Article is brought to you for free and open access by the Universitas Indonesia at ASEAN Journal of Community Engagement. It has been accepted for inclusion in ASEAN Journal of Community Engagement. 


\title{
School-based Oral Health Promotion and Intervention in AMIGA (Alfonso, Mendez, Indang, General Emilio Aguinaldo, Amadeo) Cavite, Philippines
}

\author{
Arlene Cecilia A. Alfaro ${ }^{*}$
}

a University of the Philippines Manila

Received: September 27th 2017 || Revised: November 9th \& November 23 $3^{\text {rd }}, 2017$ || Accepted: November $29^{\text {th }}, 2017$

\begin{abstract}
Dental caries affects $87.4 \%$ of Filipinos while $48.3 \%$ have periodontal disease. In most developing lowincome countries like the Philippines, more than $90 \%$ of caries cases are left untreated. Because of the aparent disparities in health, the high cost of healthcare, unaffordable and unavailable health service, there was a call for reorientation towards prevention on a mass scale by the World Health Organization. This pushed for oral health promotion in schools. Schools provide an environment ideal for introducing preventive measures for developing sustainable health and promoting change in behavior with long-term health outcome improvements. The dental interns from the University of the Philippines College of Dentistry use community-based education to assist the community in developing programs that promote, achieve, and maintain oral health. The partners tapped in the inter-local health zone of AMIGA in Cavite were elementary and high schools in the five municipalities. The schools engaged in the program depended on the priority barangay identified by both AMIGA and the University. Thus, a needs analysis was the first step in isolating the emergent oral health problem before the program draft designing stage. Consultation and presentation of students' oral health status to the stakeholders, specifically parents, teachers, municipal dentist, municipal health officer, and local government officials were scheduled so that the needed support and commitment are both realized. The programs and activities done in the partner school were Oral Screening, Atraumatic Restorative Treatments, Scaling and Polishing, Topical Fluoride Application, and Oral Health Promotion. Both preventive and curative treatment modalities were employed in addressing the dental disease. Choice of the strategy was dependent on the resources of each municipality and reflects the local government prioritization on health. The success of the programs relied heavily on the participation of all the stakeholders from organizing, financing, promotion, and implementation. Endorsement of the activities to the municipal dentist, together with referrals of specific cases not managed in the community setting was done to facilitate monitoring and evaluation.
\end{abstract}

Keywords: community dentistry; dental caries; oral health; oral health promotion; prevention

\section{Introduction}

The prevalence of dental diseases worldwide is a costly burden to health care services. In most developing low-income countries like the Philippines, the prevalence rate of dental caries is relatively high, and more than $90 \%$ of caries cases are left untreated (See Figure 1). Untreated caries in the permanent dentition was the most prevalent condition evaluated for the 2010 Global Burden of Disease Study. This has a significant impact on health, quality of life and cost to society (Bourgeois \& Llodra, 2014). As many as five billion people worldwide were estimated to suffer from dental caries/tooth decay (Petersen, Bourgeois, Ogawa, Estupinan-Day \& Ndiaye, 2005). They also found that the burden of disease and the need for care are highest in the poor, neglected or disadvantaged population groups in both developed and developing countries. In the Philippines, according to the January 2014 report by the Department of Health (DOH), $87.4 \%$ of the population have caries while $48.3 \%$ of them have periodontal disease. 


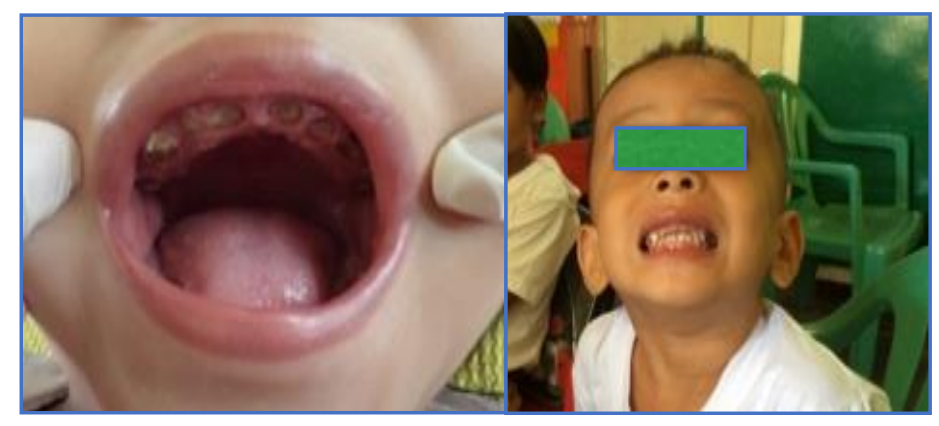

Fg. 1 Dental caries in schoolchildren in Cavite, August 28, 2015 Source: photo archive from Personal Pictures

The World Health Organization (WHO, 2007) has attributed this to the relatively available simple sugars in the diet, to fluoride experience, and to dental treatment. It was also seen that socio behavioral risk factors have significant roles in the experience of dental caries in both children and adults worldwide (Petersen et al., 2005). The key to combat this disease is to establish good behaviors of toothbrushing with fluoridated toothpaste and control of sugary snacking. Though an individual's susceptibility to this disease is observed throughout their entire life, tooth decay, for the most part, is preventable. (Bourgeois \& Llodra, 2014).

The University of the Philippines Manila is the country's Health Science Center. Its objectives are to provide leadership in education, research, and service in the various sciences and to provide healthcare of the highest quality (History of UP Manila, n.d.). The university has established the University of the Philippines Manila Community Health and Development Program (UPM-CHDP) whcih envisions an academic community imbued with social responsibility, professionalism, compassion, and sense of nationalism, facilitating socioeconomic, political and cultural development in partnership with the Filipino people. Its mission is to include health in promoting participatory socioeconomic, political, and cultural development employing the Primary Health Care Approach (Paterno, 2007). UPM-CHDP utilizes the Inter-Professional Education (IPE) among the stakeholders of the community and other units of UP Manila, one of which is the College of Dentistry (CDPII, 2016). As a state university, the University of the Philippines Manila College of Dentistry (UPCD) has the role of improving the oral health of the Filipinos. Being indebted to the Filipino people since students' college education was subsidized by taxpayers, the university has the social responsibility for promoting good oral health in the Philippines (History of UP Manila, n.d.).

\section{Theoretical Background}

\subsection{Health and Disease}

Health is a condition of complete mental, physical, and social well-being and not only the absence of disease (Preamble of the WHO Constitution, 2002). Having good oral health means you can speak, chew, eat, taste food, socialize, and ultimately enjoy life. On the other hand, having oral diseases cause suffering, pain, psychological constraints, and social deprivation that can lead to individual or society loss (Petersen et al., 2005). Ninety-seven percent (97\%) of 6-year old school children in the Philippines have poor dental habits, leading to learning difficulty (Monse \& Yanga-Mabunga 2007). This may lead to a toothache which according to the Department of Education, is the leading cause of absenteeism in schools (Araojo, 2003). Caries, the disease that triggers tooth decay, 
causes impaired chewing that may be a reason for the decreased appetite followed by weight loss, sleep problems, behavioral changes, and low school performance. Inadvertently, this may compromise the family welfare because the parents feel guilty for their children's suffering and have work absence and expenditures associated with dental treatments (Feitosa, Colares, \& Pinkham, 2005). Reports have shown a relationship between caries and financial status. Children who grew up plagued with dental caries and who have family members with serious dental caries are more likely to be at risk of having dental caries in the future. Some of the reasons identified that have led to this state are: limited to no access to dental care, lack of accessible preventive measures such as water fluoridation, supplementation of fluoride, and pit and fissure sealants, and the lack of information on the importance of oral well-being (Alazmah, 2017). Patterns of dental disease reflect distinct risk profiles across countries that are related to living conditions, lifestyles and environmental factors, and the implementation of preventive oral health schemes is needed (Petersen et al., 2005).

\subsection{Studies in the Philippines}

A National Oral Health Survey in the Philippines in 2006 revealed urgent oral needs for the $97.1 \%$ of six-year-olds with dental caries to which $84.7 \%$ exhibited symptoms of dental infection. An index was used to determine whether treatments were being given to the 4,050 children examined in this survey, which represented the twelve million public school's elementary population in the Philippines. Sixteen percent of the 12-year olds and $20 \%$ of the 6 -year olds complained of discomfort and pain in their mouths. A more recent study in the Philippines examined 1,200 schoolchildren aged 6 to 12 years and found the overall prevalence of caries to be at $92.3 \%$. Both dentitions have high prevalence: primary dentition was at $71.7 \%$ prevalence while the permanent dentition had $68.2 \%$ prevalence. What dominated the index scores were untreated decayed teeth which were reflective of the high level of unmet treatment needs (Yabao, 2005). In most developing countries, the low levels of dental caries are now rising due to the increasing consumption of sugars and inadequate exposure to fluorides. On the other hand, in most industrialized countries, a decline in caries has been observed over the past 20 years or so. This result was mostly attributed to some public health measures, including effective use of fluorides, together with changing living conditions, lifestyles and improved selfcare practices (Petersen et al., 2005).

\subsection{Ottawa charter for health promotion}

In November of 1986, the first International Conference on Health Promotion was held in Ottawa, Canada. This conference, which defined health promotion as the method of enabling people to increase control over thereby improving their health, is a response to the growing expectations for an improved public health strategy. The goal of the conference was to identify actions to achieve health for all by the year 2000 and beyond. There are three basic strategies for health promotion (WHO, 1986):

(1) Advocate - health promotion action intends to make sociocultural factors to health favorable through advocacy for health;

(2) Enable - health promotion action intends to diminish differences in current health status and ensuring equal opportunities and resources to empower people to achieve their full health potential; and

(3) Mediate - health promotion requires coordinated action from all concerned, namely: governments, health and other social and economic sectors, nongovernmental and voluntary organization, local authorities, industry and the 
Arlene Cecilia A. Alfaro | ASEAN Journal of Community Engagement | Volume 1, Number 2, 2017

media. There should be involvement of people in all walks of life as individuals, families, and communities.

\subsection{Preventive treatments}

Oral diseases, such as dental caries, are preventable. Likewise, risk factors such as smoking tobacco and excessive consumption of alcohol, bad dietary habits, and poor standard of oral hygiene, can be prevented or controlled. Despite the known low mortality rate associated with dental disease, they have a considerable effect on selfesteem, eating ability, nutrition and health both in childhood, and old age (Feitosa et al., 2005). Furthermore, the cost of traditional dental treatment of disease is expensive. The Philippine government has not included dental benefits in PhilHealth, the national health card, and the usual mode of payment for dental treatments is out-of-pocket or private health cards. Therefore, the large financial benefits of preventing dental diseases should be emphasized. What is urgently needed is to intensify public health programs through the implementation of effective oral disease prevention measures and health promotion (Reyes, 2001).

According to WHO from the Regional Oral Health Strategy in the South-East Asia Region 2013-2020, oral diseases rank fourth among the most expensive diseases to treat and most often requires costly out-of-pocket payments for patients. The treatments are focused on restorative care which is expensive and neglect the more cost-effective preventive approach focused on the population at large. Moreover, private dental care facilities are not affordable and not easily accessible to the general population. In addition to this, people cannot always depend on public dental health care service to address their basic dental needs, since it depends on resource allocation and prioritization which are usually low (WHO, 2013). Due to the evident disparities in health, the high cost of healthcare, unaffordable and unavailable health service, there was a call for reorientation towards prevention on a mass scale, by the WHO Commission on the Social Determinants of Health. This pushed for oral health promotion in schools (WHO, 2013). Schools have proven to be a powerful setting for secondary socialization. During school years, students can be accessed during this period that runs from childhood to adolescence. These are influential stages in people's lives where they develop lifelong sustainable health-related behaviors, as well as beliefs and attitudes. Globally, approximately $90 \%$ of children attend primary schools (UNESCO, 2011). Children are shown to be particularly receptive during this period, and the earlier the habits are formed, the more long-lasting the impact is. Also, the messages can be reinforced consistently throughout the school years. Students may also be taught personal skills that will guide them to make healthy decisions, to adopt a healthy lifestyle and to deal with stressful situations such as violence and conflicts (Jürgensen \& Petersen, 2013). Oral health education provides information to improve awareness that may influence the adoption of a healthier lifestyle, a good oral health behavior, and a more positive attitude. Increase in this knowledge, through health education, was found to not only to favorably influence self-reported oral health practices and behavior, but also clinical measures of oral health like oral hygiene, gingival health, and dental caries were also improved (Gauba, Bal, Jain, \& Mittal, 2013). However, a study by Patton et al. in 2006 argues that preventive strategies employed in schools should go beyond health education.

\subsection{Use of fluoridated toothbrush, fluoride varnish, and tooth brushing drills}

In the Beijing declaration in 2007, WHO and FDI World Dental Federation reaffirmed that tooth decay could be prevented with the use of fluoride, which is the single most 
effective and realistic way of reducing the burden of tooth decay in populations. Also, daily use of optimal fluoride is efficient, cost-effective, and safe. Evidence has shown that fluoride has been proven to prevent and reduce caries. The call to create national policies and programs for the automatic administration of fluoride (in the form of water and salt fluoridation) and/or the topical use of fluoride (given as affordable and effective fluoride toothpaste) was again reaffirmed in the declaration (WHO, 2007). Cost-effectiveness and efficacy of fluoride should be emphasized its promotion. The use of toothpaste has been attributed to a population-level decrease in dental caries. Though official estimates regarding the availability of fluoridated toothpaste in the Philippines are lacking, however, media would show that multinational toothpaste companies dominate the market and aggressively promote the use of fluoridated toothpaste. (Cariño, Shinada, \& Kawaguchi, 2003).

Aside from this, there are other ways to introduce fluoride to the population on a massive scale. There is an existing Department Order on the implementation of the Essential Health Care Package(EHCP) for School Children (DO 65, 2009). The EHCP or the fit for a school program in the Philippines is focused on institutionalizing supervised daily tooth brushing with fluoridated toothpaste daily hand washing with soap, and bi-annual deworming of all public schoolchildren. In 2010, a year after the release of the memo, Monse stated that the EHCP program had been successfully implemented in the Philippines covering 630,000 children in 22 provinces. She further added that the plan is for the program to reach 6 million children in the next three years. School programs have a general principle of defining clear roles and responsibilities agreed upon by both the health and education sectors. The Department of Education (DepEd) will implement the program, and the local government will finance and provide the consumables: soap, toothbrush, toothpaste, medications (Monse, Naliponguit, Belizario, Benzian, \& Helderman, 2010). However, as the local government has different priorities, cities, particularly schools, will only benefit from this if the program has an allocation in the budget. This is even though DepEd has already released the DO to all public schools in the Philippines. Eventually, the benefits of fluoride utilization to prevent tooth decay in the second component of EHCP, through tooth brushing drills, is not fully utilized. Existing government programs like this should be recognized and given priority instead of drafting numerous others that may follow suit. The University can assist in this endeavour. The University of the Philippines (UP) Charter 2008 states that as a public service university, UP shall take the lead in providing various forms of community, volunteer, and public service. They are also expected, while maintaining its standard of excellence, to provide scholarly and technical assistance to the private sector, government, and civil society (The UP Charter, 2016).

\section{Methods}

\subsection{Local Government Unit (Cavite)}

Mendez or Mendez-Nuñez is a fourth-class urban municipality located in the province of Cavite, Philippines. Its land area is 16.7 square kilometer, and as of the May 2010 census, it has a population of 28,570 . The town was originally known as 'Gahitan', which is one of the many Barrios of Indang, another municipality in Cavite. This name was derived from the word 'gahit' which means 'to cut.' Back then, the people had to cut down tall and thick cogon grass that were bountiful in the place to clear areas for the agricultural and residential purpose (Philippine Standard Geographic Code, 2017). The municipality has 24 barangays namely - Anuling Cerca 1, Anuling Cerca 2, Anuling Lejos 1, Anuling Lejos 2, Asis 1, Asis 2, Asis 3, Banayad, Bukal, Galicia 1, Galicia 2, Galicia 3, 
Miguel Mojica, Panungyan 1, Panungyan 2 Palocpoc 1, Palocpoc 2, and seven (7) barangays in the Poblacion. Honorable Fredderick A. Vida is the Mayor of Mendez and is in his second term. Dr. Jose Auditor is the Municipal Administrator (MA), Dr. Rosalina Veridiano is the Municipal Health Officer (MHO), and Dr. Romelina Aure is the Municipal Dentist (MD). These are some of the key people responsible for the health of the constituents of Mendez and for the year 2015, one of the identified groups to service was the elementary schools.

\subsection{Panungyan Elementary School}

The school comprises of 293 students from kindergarten to sixth grade with age ranging from 5 to 12 years old. One classroom is allotted for each grade level supervised by a teacher-in-charge/ adviser and classes are held from 7 am-12 pm for kindergarten students and 7 am -4 pm for the other grade levels. There is a gazebo provided by the school at the waiting area near the gate where the parents drop off and wait for younger students to finish their classes. However, most of the students go to school by themselves since the elementary school is within walking distance from Barangay Panungyan I and Panungyan II residential areas. There is a regular supply of water and electricity in the school. The school canteen sells a variety of food items, with a weekly lunch schedule which makes use of vegetables grown in the school's garden. Several sari-sari stores selling common snack food and drinks like chips, candies, biscuits, chocolates, water and flavored beverages are located outside the school premises. The school has its clinic, a small room where medical and dental records of students and teachers are stored, though this has not been updated since 2012. A small bed and toilet area and sink that has running water can be found in this room. There is no school nurse, and a trained clinicteacher is sought during emergencies. The school is located near Panungyan II Barangay Hall where Barangay Health Workers (BHWs) rotate daily, and medical interns from the UP College of Medicine are on duty every Thursday to attend to immediate medical concerns, and private medical and dental clinics can be reached by an 8-minute tricycle ride to the town proper.

The University of the Philippine College of Dentistry (UPCD) has three departments, one of which is the Department of Community Dentistry. The Department recognizes the importance of formal education in raising the standards of community dental care through its undergraduate courses on community oral health. Together with the other departments, Community Dentistry ascertains that the institutional objectives are accomplished especially in developing students who are scientifically knowledgeable, technically capable, and socially sensitive (Community Dental Practice II, 2016). Guided by the principles and concepts of Primary Health Care as the basis for programs and projects, the Department continues to adapt to the changing needs and demands of various communities on oral health. On the 5th (second semester) and 6th (first and second semester) year of the students at UPCD they take up the course Community Dental Practice I (Dentistry 165) and II (Dentistry 166), respectively. Dentistry 166 is the field practice of all senior dental interns where competencies learned from all the courses offered by the Department of Community Dentistry are applied. It is a community-based education wherein the interns actively participate in learning and working with the community (CDPII, 2016). The Dental Interns use community-based education to assist the community in developing programs that promote, achieve, and maintain oral health. One of the visions of the Department of Community Dentistry is to continuously produce excellent leaders in community dentistry who are socially sensitive in promoting wellbeing with the cooperation and supporting the involvement of many communities (CDPII, 
2016). Seven senior dental interns from the University of the Philippines College of Dentistry were deployed for the AY 2015- 2016 (See Figure 2) to the municipality of Mendez. Living with foster families, these interns stayed for four rotations with each rotation comprising of 2 and 1/2 field days from Wednesday to Friday. (Wednesday 1/2 day, Thursday and Friday whole day). According to Readings on Community Integration (Paterno, 2007), there are two reasons why an intern should integrate with the community: first, for the intern to gain an insight into the way people in a typical Filipino rural community live; and second, the health team needs to fully comprehend the health situation and changes needed to effectively mobilize the people in the community. The last, however, was a misstep for this program when it started. The municipality of Mendez has seven elementary schools, and there was no opportunity to assess the health situation of all schools to identify their needs. The priority school was handpicked by the UPCHDPAMIGA partnership under several considerations.

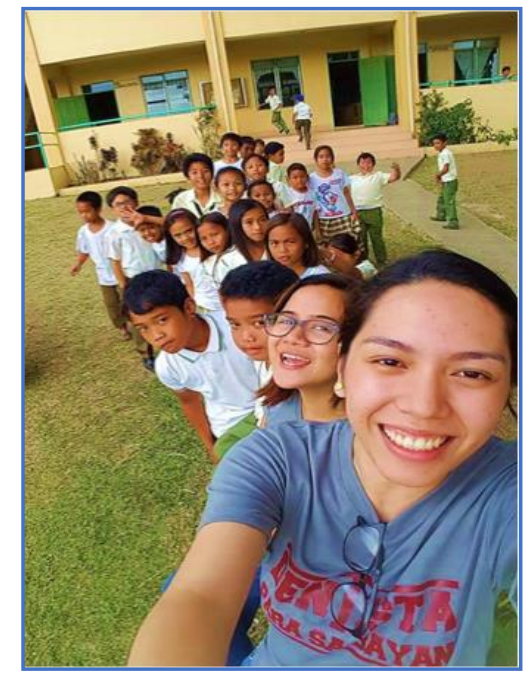

Fg. 2 Senior dental Interns deployed in Mendez, Cavite. January 27, 2016

Source: photo archive from Personal Pictures

The recommendation to create an oral health program for the school came from the Municipal Health Officer (MHO), Dr. Rosalina Veridiano with the agreement of the Municipal Dentist (MD), Dr. Romelina Aure. Other considerations with the choice of school were the proximity of the school to the dental interns' foster homes and the expressed willingness of the school principal, Mr. Joseph Ocampo, to participate. Programs and activities conducted in the school employed both preventive and curative treatment modalities. These activities were oral screening, atraumatic restorative treatment (tooth filling), scaling and polishing (teeth cleaning), and oral health education.

For the oral health education, the lessons that the interns wanted to impart to the younger students were: identification and avoidance of food that may cause tooth decay, the importance of toothbrushing, and proper toothbrushing technique. This was done through room-to-room storytelling using the children's book 'Joboy's Dream' for grades 1-3 students (5-8-year-olds). A question and answer session took place at the end of the story to evaluate the students understanding. The questions were asked in the local language and translated into: (a) What were the foods that Joboy ate that caused his teeth to hurt? (b) Why do the worms love stay inside the tooth of Joboy? (c) How often should you brush your teeth? (d) What can we find in the toothpaste that will strengthen our teeth? (e) What did you learn from the story? Toothbrushes and toothpaste were given 
as prizes. The grades 4-6 pupils (aged 9-11) were gathered in one room, and a short animated oral health video was shown. The objective was to increase the awareness of the pupils on the importance of brushing, the frequency of brushing, the role of fluoride, the correct amount of toothpaste, and proper toothbrushing technique. A 5-item multiple choice questionnaire was given as pretest and posttest to evaluate their understanding of the lesson. The questions were written in the local language and translate into: (1) How many times are you recommended to brush your teeth in a day? (2) What important ingredient do you look for in the toothpaste before you buy it? (3) How much toothpaste do you apply on your toothbrush? (4) What areas/surfaces of the teeth do we brush? (5) What is the proper way of brushing? All the students were taught proper tooth brushing through demonstration with a tooth model and toothbrush.

The students' oral health status was determined by conducting an oral screening using tongue depressors and handheld flashlights in a designated classroom using mono block chairs. Teachers were instructed to have the parents of the students sign an informed consent form before any treatment is to be given and students who failed to bring a signed consent form on the scheduled dates of screening and treatment were not included in the program. The day before the oral screening, the dental interns together with the Community Dentistry faculty preceptors did a calibration to standardize diagnosis for each tooth condition. The total population of 293 students was screened in two separate rotations of interns in August and October 2015 (approximately 5 hours of their field duty). The oral health data, specifically the Decayed, Missing, and Filled Teeth (DMFT) was updated in the students' dental forms. DMFT describes the dental caries severity in an individual. It is calculated by adding the number of decayed (D), missing (M) and filled (F) teeth and describes the individual's dental caries experience until the day of oral examination. The sum of all the DMFT values divided by the total number of individuals in the sample provides the average DMFT for the population (Burgois \& Lloda, 2014). In addition to the DMFT charting, notes were written on the chart for decayed teeth that can be restored/filled in the community setting using Atraumatic Restorative Treatment (ART). The interns presented a written and oral report of the findings from the screening to relevant stakeholders for funding. Upon acquisition of requested materials from the local government unit, curative treatments were scheduled and given on two separate days a few months after the first screening in October 2015 and January 2016. The treatments rendered were an atraumatic restorative treatment (tooth filling), scaling and polishing (teeth cleaning), and pit and fissure sealants.

\section{Result and Discussion}

The Philippine Health System can be described as a dual health system in providing health service. First, the public sector comprises of the Department of Health (DOH) and the Local Government Units(LGU) and the second is the private sector. The DOH was the sole financial and administrative authority over the entire health system in the Philippines before the devolution wherein all health programs for the people came from them (Paulino, 2008). During the devolution, the LGUs, through the Local Government Code of 1991 - Republic Act No 7160- was given more power, authority, and responsibility as well as resources at their disposal. After 1991 the health system was functionally divided into the municipal/city, province and the DOH administrations and decisions on financial and administrative operations were given to each body as they govern over their respective areas (Paulino, 2008). This changed the delivery of health services as it gave LGUs the responsibility for and financial management of their health activities, with the DOH providing guidance and advice. 
A novel approach to the diverse and fragmented health system in the country is the establishment of the Inter-Local Health Zone (ILHZ). The Local Government Code states that through appropriate ordinances, the local government units may group themselves to consolidate or coordinate their efforts, purposes, and services that are commonly beneficial to them (The Local Government Code of the Philippines, 1991). One of this established ILHZ is in Cavite which comprise of the municipalities of Alfonso, Mendez, Amadeo, Indang, General Aguinaldo, and Amadeo aptly called AMIGA. In 2013, The University of the Philippines Manila Community Health and Development Program (UPCHDP) had signed a 5-year memorandum of agreement with AMIGA. Development and implementation of programs to improve the health of the people in the AMIGA provinces are one of the concerns of this partnership. The partners tapped in the interlocal health zone of AMIGA in Cavite were the elementary and high schools in the five municipalities. Though programs are similar among municipalities, specific activities depended on the resources of each municipality and reflected the prioritization of the local government on health. Likewise, it also depended on the support and commitment of the stakeholders. In the municipality of Mendez, there are ten public schools. Seven are elementary schools, namely- Anuling Elementary School, Asis Elementary School, Gahitan Elementary School, Galicia Elementary School, Mendez Central Elementary School, Palucpoc Elementary school, and Panungyan Elementary School. Three are High SchoolsAnuling National High School, Asis National High School, and Palocpoc National High School. For the AY 2015-2016, the Dental Interns developed a program with the Panungyan Elementary School.

The oral health program was seen by the teachers, parents and students as a school program. This idea facilitated the participation of the students, parents, and teachers like any school activity - a requirement that needs to be fulfilled. They were not part of the conception of the program but were merely at the receiving end. Thus, it was not given the importance expected from community-based programs. Oral health is essential to an individual's general health, and well-being at every stage in their life and this should be recognized by public health professionals and policy makers (Mason, 2010). While this was seen in Panungyan where the recognition/identification of the need to address the oral health problem in the school came from the Municipal Health Officer, Municipal Dentist, and the Principal, Mason continued to state that ownership and commitment to the program are important for its success (2010). This ownership should not just come from those in office but also from the teachers, students, and parents. Since the criteria recognized by the community was already established - recognition from the community leaders - the other criteria were assessed: cost-effective, sufficient community resources, the focus is the identified need and accepted by the community. For the program to be drafted based on the said criteria, the oral health status was determined.

One way to fully comprehend the health situation in the elementary school was during the oral health assessment by the interns using the school's existing dental records where the (DMFT) for each student was updated. DMF Index is a quantitative expression of a person's caries experience per tooth where CAPITAL letters of the acronym represented permanent teeth (DMF) while small letters pertain to primary teeth (dmf). There are several pints of information that can be provided by the DMF Index: (1) the number of individuals affected by dental caries, (2) the number of teeth recommended for treatment, (3) the number of teeth that have been extracted due to dental decay/caries, (4) the percentage of teeth that have been treated (5) the data is helpful in evaluating and creating oral health programs, (6) the index also provides important data in determining the effect of various preventive dental treatments, and (7) the index helps the governing 
bodies in deciding if additional dental resources and financial assistance is needed for the continuous provision of preventive measures needed in the community. In addition to the DMFT charting, identified decayed teeth that can be restored/filled in the community setting using Atraumatic Restorative Treatment (ART) were tabulated. ART is a procedure where caries/decay are manually excavated or removed with hand instruments and teeth are restored/ filled with Glass Ionomer or if restoration should be done at a dental clinic setting with the aid of a dental drill and light cured restorative filling. Due to the limitations of rendering dental restorations in communities, teeth not indicated for ART were not addressed.

The first session of the oral screening coincided with the municipal-wide sports fest at the Mendez Central Elementary School, so the 48 representatives from Panungyan Elementary School were not screened at that time. They were all screened on the second session. The results of the oral screening are presented in Table 1, high DMFT (index for primary teeth) was seen from Kinder to Grade 2. There are two sets of dentitions an individual will have throughout his life: 20 primary teeth and 32 secondary teeth. The secondary teeth will replace the primary at certain stages in life naturally, through exfoliation, or through extraction. These students are aged 5-8 and are in the mixed dentition stage where both primary ( $\mathrm{dmf}$ ) and secondary(DMF) teeth are present in the oral cavity. It is alarming to note that the average DMFT for this group of students is eight which is almost half the number of their average 20 primary teeth. And at least 1 of their permanent teeth is already decayed.

\begin{tabular}{|c|c|c|c|c|c|c|}
\hline & $\begin{array}{l}\text { Total No. } \\
\text { of } \\
\text { Students }\end{array}$ & $\begin{array}{c}\text { Total number } \\
\text { of students } \\
\text { screened }\end{array}$ & $\begin{array}{c}\mathrm{DMF} \\
\mathrm{T}\end{array}$ & $\begin{array}{l}\text { Average } \\
\text { DMFT (in } \\
\text { whole } \\
\text { numbers) }\end{array}$ & DMFT & $\begin{array}{c}\text { Average } \\
\text { dmft (in } \\
\text { whole } \\
\text { numbers) }\end{array}$ \\
\hline Kinder & 39 & 22 & 2 & $(0.09) 1$ & 176 & 8 \\
\hline $\begin{array}{l}\text { Grade } \\
1\end{array}$ & 43 & 38 & 16 & $(0.42) 1$ & 318 & $(8.36) 9$ \\
\hline $\begin{array}{l}\text { Grade } \\
2\end{array}$ & 51 & 47 & 51 & $(1.08) 1$ & 330 & $(7.02) 7$ \\
\hline $\begin{array}{l}\text { Grade } \\
3\end{array}$ & 26 & 23 & 24 & $(1.04) 1$ & 114 & $(4.95) 5$ \\
\hline $\begin{array}{l}\text { Grade } \\
4\end{array}$ & 47 & 46 & 81 & $(1.76) 3$ & 161 & $(3.50) 4$ \\
\hline $\begin{array}{l}\text { Grade } \\
5\end{array}$ & 43 & 41 & 97 & $(2.36) 3$ & 70 & $(1.70) 2$ \\
\hline $\begin{array}{l}\text { Grade } \\
6\end{array}$ & 44 & 43 & 106 & $(2.46) 3$ & 16 & $(0.37) 1$ \\
\hline Total & 293 & 260 & 377 & $1.45(2)$ & 1,185 & $(4.55) 5$ \\
\hline
\end{tabular}

The dental charts were collated, and students with teeth indicated for ART were identified per year level. The grade level with the most number of students in need of ART is grades 1 and 2 (See Table 2). Consultation and presentation of the oral health status of the students to the stakeholders, specifically parents, teachers, municipal dentist, municipal health officer, and local government officials were scheduled so that the needed support and commitment were both realized. 
Table 2. Number of students screened for Atraumatic Restorative Treatment (ART)

\begin{tabular}{lc}
\hline Grade Level & $\begin{array}{c}\text { Total number of students with teeth } \\
\text { indicated for ART }\end{array}$ \\
\hline Kinder & 9 \\
Grade 1 & $\mathbf{2 2}$ \\
Grade 2 & $\mathbf{2 6}$ \\
Grade 3 & 6 \\
Grade 4 & 13 \\
Grade 5 & 7 \\
Grade 6 & 8 \\
Total & $\mathbf{9 1}$ \\
\hline
\end{tabular}

On the second rotation of the interns in October 2015, results of the screening (Table 1 and 2) were presented to the MHO and MD, and the recommendations, as well as the need for intervention in the form of ART were advised. The MHO, in the same meeting, asked for a formal letter of request from the Interns which included the data from the screening as well as a budget proposal for the oral health intervention activities to which the interns complied. Though the needs are maybe alarming, protocols had to be followed when dealing with government agencies. The 3 basic strategies for health promotion were also seen in this situation where first, we have advocated for health (MHO, MHD, Principal, Interns) second, enabling the school's (students, teachers, and parents) to have an equal opportunity to receive oral health interventions and third strategy to mediate and to demand coordinated action through all concerned stakeholders including the government.

The interns were also informed as it was already the last quarter of the year, so the budget request was included for the year 2016 and not 2015. It was also agreed upon that due to limited budget and human resource ( 7 interns), the program should focus on the elementary students most in need of the treatment. The students who received treatment were supposed to be only from Kinder, Grade 1, 2, and 3 but on the second treatment day, those who had signed Informed Consent Forms (ICFs) were accommodated. ART per tooth takes around 20-30 minutes, and since more than one tooth was treater per student, each student took from 1 to $11 / 2$ hours. Because of many students to be treated by the interns, the ART was conducted in 2 batches (Thursdays) on the 3rd (January 2016) and 4th rotation (March 2016) of the Interns. The Rural Health Unit (RHU) headed by the MHO and the school provided the materials while the Senior Dental Interns (assisted by the 11 Junior Dental Interns) served as a human health resource.

The students who needed ART came on the treatment day with their signed ICFs. The school allotted one classroom with ample lighting and a nearby water source for the treatment venue, a room that was set up with portable dental chairs provided by UPCD (See Figure 3). There was a 5 and 7-month gap from the oral screening, and treatment days and because the progression of caries is fast in children, teeth that were originally diagnosed for ART have become non-restorable, only 25 of the originally diagnosed 91 were filled (See Table 3). Despite the early announcement of the activity, several students were absent, some students did not have a signed ICF, and some parents opted not to have their child undergo treatment. This is an example of a misinformed community that failed to see the importance of the program or they simply did not understand. There was a gap in communication between the providers and the recipients because this was simply how it was seen- there were two ends when there should have been a partnership. 


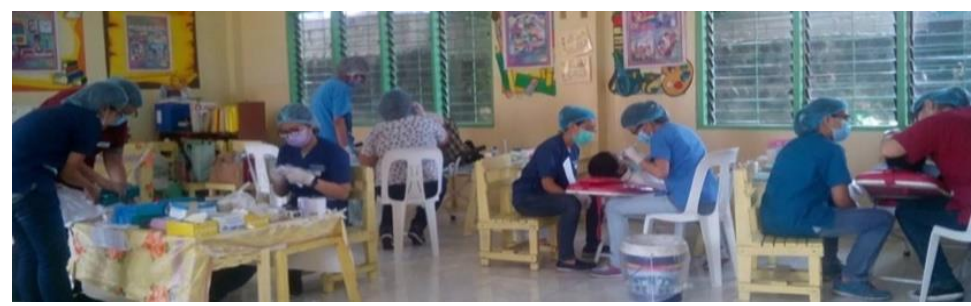

Fg. 3 Dental treatment at Panungyan Elementary School in Mendez, Cavite, January 27, 2016. Source: photo archive from Personal Pictures

For students who had signed ICF but whose teeth were not indicated for ART anymore, scaling and polishing or dental cleaning were done instead. Others received pit and fissure sealants, a preventive measure against caries, with the use of Glass Ionomer. Oral health instruction in the form of tooth brushing demo was given after every treatment. A summary of the treatment provided is seen in Table 3. Endorsement of the activities to the municipal dentist, together with referrals of specific cases not managed in the community setting was done to facilitate monitoring and evaluation. There was continued communication with the dentist and school principal until a year after.

Table 3. Summary of treatment rendered

\begin{tabular}{llllll}
\hline Grade level & $\begin{array}{l}\text { Total number } \\
\text { of students } \\
\text { with teeth } \\
\text { indicated for } \\
\text { ART }\end{array}$ & ART & $\begin{array}{l}\text { Scaling and } \\
\text { Polishing } \\
\text { (S\&P)/ } \\
\text { Dental } \\
\text { cleaning }\end{array}$ & $\begin{array}{l}\text { Pit and } \\
\text { Fissure } \\
\text { Sealants } \\
\text { (PFS) }\end{array}$ & $\begin{array}{l}\text { Total } \\
\text { number of } \\
\text { students } \\
\text { treated with } \\
\text { ART, S\&P, } \\
\text { PFS }\end{array}$ \\
\hline Kinder & 9 & 4 & 0 & 1 & 5 \\
Grade 1 & 22 & 9 & 4 & 1 & 14 \\
Grade 2 & 26 & 4 & 4 & 3 & 11 \\
Grade 3 & 6 & 2 & 1 & 1 & 4 \\
Grade 4 & 13 & 4 & 3 & 1 & 8 \\
Grade 5 & 7 & 1 & 0 & 0 & 1 \\
Grade 6 & 8 & 1 & 8 & 1 & 10 \\
Total & $\mathbf{9 1}$ & $\mathbf{2 5}$ & $\mathbf{2 0}$ & $\mathbf{8}$ & $\mathbf{5 3}$ \\
\hline
\end{tabular}

The school is also a recipient of the wash facility project of the Mayor that was started in March 2015. Back in early 2015, the Community Dentistry faculty and dental interns of AY 2014-2015 gave a presentation on the Essential Health Care Program (EHCP) under D0 65, s. 2009 at a meeting called for by Mayor Vida. The attendees were teachers and principals of the ten public schools in the municipality of Mendez. After this meeting, the Mayor provided funds for the construction of washing facilities for the ten schools in Mendez in the hopes that provision of a facility will be the first step in the full implementation of EHCP. To this date, however, 21 months after, none of the ten washing facilities have been completed. All are in similar stages of construction, $70 \%$ of the structure is complete according to the municipal engineer, but are on hold until additional funding is received. This was envisioned to be a good opportunity to address the oral health concerns of Mendez since daily supervised toothbrushing drills with fluoridated toothpaste has been proven to reduce caries progression. 
In Scotland, a 2-year school-based daily fluoridated toothpaste brushing program in school children aged 5 with high caries risk showed a $56 \%$ decrease in caries progression of the permanent first molar (Curnow, Pine, Burnside, Nicholson, Chesters, \& Huntington, 2002). In a similar study in an elementary school in Indonesia, a school-based brushing program with fluoride toothpaste, which was conducted for 3 years, resulted in up to $40 \%$ reduction in caries (Adyatmaka, Sutopo, Carlsson, Bratthall, \& Pakhomov, 1998). To prepare the school for the implementation of tooth brushing drills, the dental interns taught eight students, selected by the teachers, the proper way of tooth brushing so they can be a certified 'Fluoride Patrol.'

During the first rotation, the dental interns had a meeting with the medical interns and pediatric residents. The pediatric residents introduced a project called 'Bulilit Health Scouts' where the goal was to train select students on proper hygiene and body health. They will serve as models for their classmates where they are given the responsibility not only to share what has been taught to them but also to regularly remind the student body the importance of having good health. Part of this project is a program called 'Fluoride Patrol' where the selected students were trained and enlightened about the importance of oral health and impart proper tooth brushing (See Figure 4). They will serve as a guide for the different grade levels once the daily tooth brushing drills are implemented upon completion of the previously mentioned wash facility.

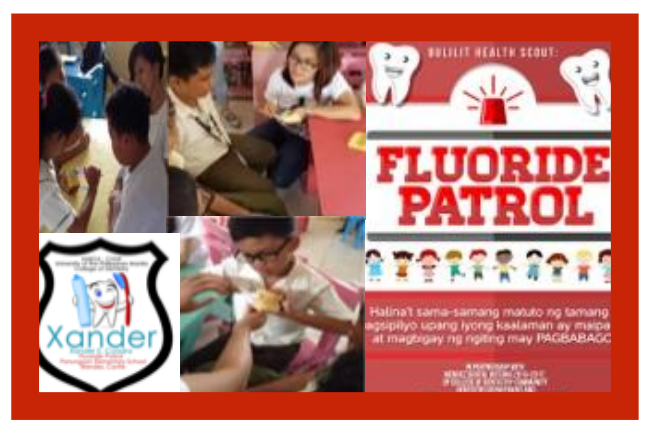

Fg. 4 Training of Bulilit Health Scouts on proper Toothbrushing. October 8, 2015 Source: photo archive from Personal Pictures

For oral health promotion, carefully chosen animated films (See Figure 5) both downloadable and made by the interns were shown. Also, storytelling and role-playing and games were utilized. Consideration was given to students' level of understanding. Room to room oral health education was also conducted with lessons taught by the junior interns, and a pretest and posttest were given.

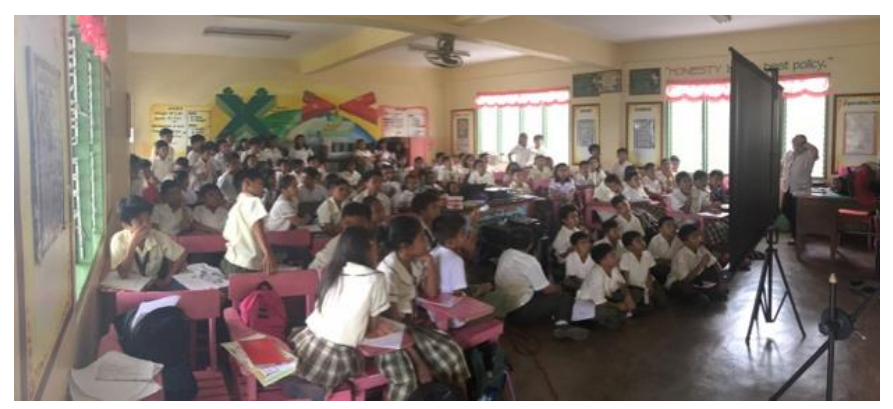

Fg. 5 Film showing for oral health promotion in a classroom at Panungyan Elementary school in Mendez, Cavite. March 04, 2016.

Source: photo archive from Personal Pictures 
Based on the collected data from the tests, most students learned the proper toothbrushing technique taught to them by the dental interns during the room-to-room activities (grades 1 to 3 ) and the animated video presentation (grades 4 to 6 ) on September 8, 2016. Most of the students also brushed their teeth twice or more daily (93.65\%) with fluoridated toothpaste (86.57\%). In the question about the correct amount of toothpaste, most of the students chose the illustration of the pea-sized amount $(63.05 \%)$ as their answers. The correct answer, $1 \mathrm{~cm}$ or half the length of the tooth brush bristles (30.16\%), were mostly from grade 3 students. For the last question, most of the students (92.06\%) answered that there are three surfaces of teeth (front, back, top) to be brushed properly (82.54\%) within two minutes. Return demonstration of 10 volunteer students for the proper brushing technique validated the attentiveness during the discussion.

For the toothbrushing demonstration, most of the Grade 1 students brought a toothbrushing kit that they used in the actual demonstration. The introduction of the 'no rinse technique' after brushing to prolong the contact of fluoride with the teeth was a new concept to the whole student body and will take a while before this is fully practiced. The teachers were also taught this concept so they will be able to guide and monitor the students. All grade levels were observed to be active and responsive during the storytelling session. However, during one of the room-to-room oral health promotion activity in the $6^{\text {th }}$ grade, none of the students were listening, and the interns had a hard time getting the students to participate. Consequently, the activity was halted halfway. That was one of the challenges in the early years of program implementation, appropriateness of oral health promotion in the community settings, such as engagement of the younger students is different from the 12-year olds. That is the importance of needs analysis which was not done in the school before implementation of the program.

The objectives of the program, to reduce the incidence of caries through dental treatments and oral health promotion and thereby improving the overall oral health status of the school, were genuine and cannot be questioned. The error, however, was in the manner of delivery to uninformed individuals who have not, at that point, recognized that they are having oral health problems. It was not an expressed need but rather an imposed need by the MHO, MD, Principal, and interns who had the good intention to give service to the school. Though it may appear as an afterthought, the program took a step back from the treatments and conducted Focus Group Discussions (FGDs) and interviews with the students, parents, and teachers which helped identify what the students wanted to learn, and the teachers in turn guided the interns on the educational materials to be produced so that it can be a part of their health class. The topics that interested the students expressed in the FGDs were like those taught by the interns, but the delivery was adjusted by incorporating games, role-playing, and more familiar animated videos.

A few months after the treatments at the school, and based on the results of these interviews and FGDs, storytelling classes for Kindergarten through 3rd grade were again conducted by the succeeding batch of dental interns. Coloring activities and games on oral health topics supplemented the information given. Moreover, discussions were also conducted at the end of each session to reinforce their new knowledge. The teachers were also present in the activities to observe both the Interns and the student's response and feedback were given to the interns so they can improve their storytelling skills. Thus, the interns were also learning from the community, which was one of the goals of community field practice. A second goal was achieved with the transfer of knowledge and materials when the story books were given to the teachers for them to continue the lessons on their 
own for the coming years. The materials for the games were also left to be used during their health activities.

The students who have undergone ART were scheduled for follow up in two sessions at the school clinic. Those who came for a checkup had a positive attitude to oral health and was evident in the brushing habits that were both self-reported and verified through the parent/ guardian that accompanied them. However, the checkup revealed retained and badly broken down primary teeth impinging on the gingiva and impeding full eruption of the secondary teeth. These were noted in the dental charts, and a list was given to the municipal dentist to be scheduled at the Rural Health Unit in the town proper for extraction. Coordination and endorsement were done with the principal and clinic teacher and the principal offered to bring the students to the clinic if need be, which showed ownership in both the school and municipal dentist. Thus, the school and the interns can now step out of the picture.

In the Philippines, there are limited human and financial resources that would allow for traditional curative dental approach, but the $87.4 \%$ caries prevalence cannot be ignored. Although health professionals want to address this problem, change cannot be made without participation from some stakeholders. According to the former CHDP Director Dr. Elizabeth Paterno, though well-meaning to begin with, health programs are often imposed upon the members of the community by their leaders, the government, or organizations. Because of this, most of the members need to be convinced that change is indeed needed. Based on the experiences of many development workers in the past, significant change and improvement in people's situation are observed to be achieved if the people themselves do something about their situation (Paterno, 2007).

\section{Conclusion}

The school-based oral health promotion and intervention program implemented in Panungyan Elementary School can be considered successful based on the Ottawa charter definition of health promotion as the process of enabling people to increase control over and improve their health as well as the 3 basic stages of health promotion - advocate, enable, and mediate. The school (students, parents, and teachers), with the leadership of their school principal, took it upon themselves to hold a fund-raising activity to fund their washing facility and a part of the school budget will also be allotted for this. Meanwhile, the fluoride patrol continues to teach their fellow students the importance of toothbrushing. The teachers have also incorporated into their lesson plan the importance of oral health towards the improvement of their general health. These actions suggest that the school has taken ownership of the program. They have recognized the need to address oral health problems, and they have taken on that responsibility.

The succeeding senior dental interns for AY 2016-2017 are duplicating this schoolbased oral health promotion, and intervention in other schools and they have learned, from the previous intern's reports, of the challenges they should face. The dental interns have learned not to plunge into activities if there is no $100 \%$ readiness, which means that the school and all stakeholders must acknowledge and accept their roles and responsibilities in any program. They must be able to read signs if the stakeholders and/or the community are not yet ready. If this can be realized by the interns at the end of their community field practice, then they have learned how dental public health should be approached.

What is being done in the AMIGA municipalities in Cavite, Mendez for one is to engage the local community to recognize that the oral health situation, particularly among schoolchildren, is a concern. However, they can be a part of the preventive action. For the 
Arlene Cecilia A. Alfaro | ASEAN Journal of Community Engagement | Volume 1, Number 2, 2017

next two years, UPM CHDP and UPCD will continue to support communities attain increasing capacities for their health care and development. Because in developing community-based programs like this school-based approach to oral health promotion and intervention, all stakeholders should be involved in planning up to monitoring and evaluation. While the goal of the University is to assist the community, the sustainable of these programs are in the hands of the community members themselves.

\section{Acknowledgements}

I would like to thank all the stakeholders from the University of the Philippines Manila and the municipality of Mendez in Cavite, especially the Mendez Dental Interns, who inspired me to write this paper.

\section{References}

Adyatmaka, A., Sutopo, U., Carlsson P., Bratthall, D., \& Pakhomov, G. (1998). School-based primary preventive program for children. Affordable toothpaste as a component in primary oral health care. Experiences from a field trial in Kalimantan, Barat, Indonesia. Geneva: WHO.

Alazmah, A. (2017). Early childhood caries: A review. The Journal of Contemporary Dental Practice, 18(8), 1-6. Doi: 10.5005/jp-journals-00000-0000

Araojo J.R. (2003). Philippine country report on school health promotion programme. Proceedings of the 2nd Asian conference on oral health promotion for school children: Prospectus for our future generation (pp. 103-110). Ayyuthaya Bangkok: Thammasat University.

Bourgeois, D.M. \& Llodra, J.C. (2014). Global burden of dental condition among children in nine countries participating in an international oral health promotion programme, 2012-2013. International Dental Journal ,64(Suppl. 2), 27-34. doi: 10.1111/idj.12129

Cariño K.M., Shinada K., \& Kawaguchi Y. (2003). Early childhood caries in northern Philippines. Community Dent Oral Epidemiology, 31, 81-89.

Community Dental Practice II (CDPII), 11 th Edition. Edited by: Santos,J.K.R. (2016) for School Year 2015-2016 [Unpublished manual]. Manila, Philippines.

Curnow, M.M., Pine, C.M., Burnside, G., Nicholson, J.A., Chesters, R.K., \& Huntington, E. (2002). A randomized control trial of the efficacy of supervised tooth brushing in high-caries-risk children. Caries Res, 36(4), 294-300.

Department Order No. 65, s. 2009 - Implementation of Essential Health Care Program (EHCP) for the School Children. (n.d.). Retrieved from http://www.deped.gov.ph/orders/do-65-s-2009

Feitosa, S., Colares, V., \& Pinkham, J. (2005). The psychosocial effects of severe caries in 4-year-old children in Recife, Pernambuco Brazil. Cad Saude, Rio de Janeiro, 21(5), 1550-1556. 
Gauba, A., Bal, I. S., Jain, A., \& Mittal, H. C. (2013). School based oral health promotional intervention: Effect on knowledge, practices and clinical oral health related parameters. Contemporary Clinical Dentistry, 4(4), 493-499. http://doi.org/10.4103/0976-237X.123056

History of UP Manila. (n.d.). Retrieved from https://www.upm.edu.ph/node/36

Jürgensen, N. \& Petersen, P.E. (2013). Promoting oral health of children through schools - Results from a WHO global survey 2012. Community Dental Health, 30, 204-218. Doi: 10.1922/CDH_3283Petersen15

Mason, J. (2010). Concepts in Dental Public Health $2^{\text {nd }}$ edition. Baltimore, MD: Lippincott Williams \& Wilkins.

Monse, B., Naliponguit, E., Belizario, B., Benzian, H., \& Helderman, W.V.P. (2010). Essential health care package for children- the 'Fit for School' program in the Philippines. International Dental Journal, 60, 1-9. Doi:10.1922/IDJ_2420Monse09

Monse B. \& Yanga-Mabunga M.S. (2007) The National Oral Health Survey from the Philippines Urgent Oral Needs. Developing Dentistry, 8, (1)

National Survey on Oral Health and Nutritional Status in the Philippines (2006). Philippine Department of Education. Retrieved from http://www.doh.gov.ph/dental-health-program

Paterno, E.R. (2007) Readings on Community Integration for Community Health and Development Program. [Unpublished manual]. University of the Phhilippines Manila, Manila, Philippines.

Patton, G. C., Bond, L., Carlin, J. B., Thomas, L., Butler, H., Glover, S., Catalano, R \& Bowes, G. (2006). Promoting Social Inclusion in Schools: A Group-Randomized Trial of Effects on Student Health Risk Behavior and Well-Being. American Journal of Public Health, 96(9), 1582-1587. http://doi.org/10.2105/AJPH.2004.047399

Paulino, C.R. (2008). Technical assistance to the health sector policy support programme: Manual for health reform coordination: Final report. Retrieved from http://www.doh.gov.ph/sites/default/files/publications/DevelopmentoftheManu alofLocalReformCoordination.pdf

Petersen, P.E., Bourgeois, D., Ogawa, H., Estupinan-Day, S., \& Ndiaye, C. (2005). The global burden of oral diseases and risks to oral health. Bull World Health Organization, 83(9), 661-669.

Philippine Standard Geographic Code. (2017). PSGC: Mendez. Retrieved from http://nap.psa.gov.ph/activestats/psgc/municipality.asp?muncode $=042114000 \&$ regcode $=04 \&$ provcode $=21$ 
Arlene Cecilia A. Alfaro | ASEAN Journal of Community Engagement | Volume 1, Number 2, 2017

Reyes, B.P. (2001) The dental health services after Department of Health Re-engineering (Progressive or retrogressive act?). Journal of the Philippine Dental Association, 53(2), 21.

The Local Government Code of the Philippines Book 3 Local Government Units. (1991). Retrieved From http://www.dilg.gov.ph/PDF_File/reports_resources/dilg-reportsresources-2016120_5e0bb28e41.pdf

The Preamble of the Constitution of the World Health Organization (2002). Bull World Health Organ, 8(12), 983-984. Retrieved from http://dx.doi.org/10.1590/S004296862002001200015

The UP Charter. (2008). Retrieved from www.up.edu.ph/about-up/the-up-charter/

United Nations Educational, Scientific and Cultural Organization (UNESCO) (2011): UNESCO Institute for Statistics. Global Education Digest 2011. Montreal: UNESCO.

World Health Organization (1986). Ottawa Charter for Health Promotion. Retrieved from www.who.int/healthpromotion/conferences/previous/o59ttawa/en/

World Health Assembly (2007). Resolution WHA 60.17 Oral health: action plan for promotion and integrated disease prevention. In: Sixtieth World Health Assembly, Geneva. Geneva: WHO.

World Health Organization Regional Office for South-East Asia 2013-2020 (2013). World Health House Indraprastha Estate, Mahatma Gandhi Marg, New Delhi-110002, India. Retrieved from www.searo.who.int

Yabao, R.N., Duante C.A., Valendria F.V., Lucas M., Kassu A., Nakamori M., \& Yamamoto S. (2005). Prevalence of dental caries and sugar consumption among 6-12-y-old schoolchildren in La Trinidad, Benguet, Philippines. European Journal of Clinical Nutrition, 59, 1429-1438. Doi:10.1038/sj.ejcn.1602258 